\title{
Evidence-based medicine and the role of antioxidants in physically stressed people : [Letter]
}

\section{Hemilä, Harri}

2009

Hemilä , H 2009 , ' Evidence-based medicine and the role of antioxidants in physically

stressed people : [Letter] ' , Nutrition Reviews , vol. 67 , no. 1 , pp. 61-63 . https://doi.org/10.1111/j.1753-4887.2008.

http://hdl.handle.net/10138/228068

https://doi.org/10.1111/j.1753-4887.2008.00134.x

acceptedVersion

Downloaded from Helda, University of Helsinki institutional repository.

This is an electronic reprint of the original article.

This reprint may differ from the original in pagination and typographic detail.

Please cite the original version. 


\section{Evidence-based medicine and the role of antioxidants in physically stressed people}

Harri Hemilä, $\mathrm{MD}, \mathrm{PhD}$

Letter-to-the-editor: Nutrition Reviews

\section{Published as:}

Hemilä H. Evidence-based medicine and the role of antioxidants in physically stressed people. Nutr Rev. 2009 Jan;67(1):61-3; author reply 64. doi: 10.1111/j.1753-4887.2008.00134.x. https://doi.org/10.1111/j.1753-4887.2008.00134.x https://www.ncbi.nlm.nih.gov/pubmed/19146508

\section{Comment on:}

Nieman DC. Immunonutrition support for athletes.

Nutr Rev. 2008 Jun;66(6):310-20. doi: 10.1111/j.1753-4887.2008.00038.x.

https://www.ncbi.nlm.nih.gov/pubmed/18522619

Harri Hemilä, MD, PhD

Department of Public Health

University of Helsinki,

Helsinki, Finland

harri.hemila@helsinki.fi

http://www.mv.helsinki.fi/home/hemila/ 
Proponents of evidence-based medicine emphasize that conclusions regarding the effects of interventions should be based on systematic reviews of the literature and should focus on clinically relevant outcomes (1). Neither of these demands was fulfilled in Nieman's recent discussion of the effects of antioxidants on respiratory infections in physically-stressed people (2).

We carried out a systematic review of the effect of vitamin $C$ supplementation on the common cold and identified six controlled trials with participants under heavy acute physical stress (3). Four of these were with marathon runners - three in South Africa (4-6) and one in the USA (7) - one was with schoolchildren in a skiing camp in the Swiss Alps (8), and one was with Canadian soldiers in a Northern training exercise (9). We pooled the results of these six trials and found that vitamin $\mathrm{C}$ supplementation reduced the incidence of common cold on average by $50 \%(95 \%$ confidence interval $[\mathrm{CI}]:-62 \%$ to $-34 \%$ ). In contrast, vitamin $\mathrm{C}$ had no effect on common cold incidence in the general population (3).

Nieman writes just two sentences about the trials testing the effect of antioxidants on clinical infection outcomes: "Several double-blind placebo studies of South African ultramarathon runners demonstrated that vitamin C (but not $E$ or beta-carotene) supplementation (about $600 \mathrm{mg} /$ day for 3 weeks) was related to fewer reports of URTI [upper respiratory tract infection] symptoms [3 references]. This finding, however, was not replicated by other research teams even when $1 \mathrm{~g}$ of vitamin C was consumed for 2 months prior to a marathon [1 reference]" (2, p. 313). The references in these two sentences are erroneus. Of the first three references, one is to Nieman's own study on quercetin and cytokines with no relationship to the sentence, another is to a US trial that administered $1 \mathrm{~g}$ of vitamin $\mathrm{C}$ per day for 2 months prior to a marathon (7), and only one is to a trial in South Africa (5). The reference at the end of Nieman's second sentence is to a vitamin E trial that has nothing to do with vitamin $\mathrm{C}$ and the common cold.

It seems that Nieman was trying to argue that, while Peters et al. $(4,5)$ and Moolla $(6)$ reported that vitamin $\mathrm{C}$ supplementation prevented colds in ultramarathon runners in South Africa, Himmelstein et al. (7) challenged or refuted their findings. There is, however, no justification for such an argument. Firstly, the Himmelstein trial was small and the $95 \%$ CI (from $-65 \%$ to $+71 \%$ ) is fully consistent with the average effect of the six trials, the results of which show no statistical heterogeneity (3). Secondly, Nieman ignores two trials falling into the same group $(3,8,9)$. Thirdly, the Himmelstein trial is methodologically the weakest of the six trials (3), due to an extreme and divergent drop-out rate. They started with 52 marathon runners in two groups, but $42 \%$ (22 of 52) of the vitamin $\mathrm{C}$ group, and $75 \%$ (38 of 52) of the placebo group dropped out during the trial $(\mathrm{P}=$ 0.003 for the difference in drop-out rates). On the basis of such a serious weakness, the Himmelstein trial might be excluded from the meta-analysis; however, that would lead to a greater effect by vitamin $\mathrm{C}$ because the Himmelstein trial found the smallest effect among the six trials (3). Thus, Himmelstein's trial does not challenge our summary estimate that in six placebo-controlled trials with participants under heavy acute physical stress vitamin $C$ halved the risk of common cold (3). Cochrane reviews are regularly updated and the Cochrane Database provides the possibility to comment on the reviews. If Nieman considers that our estimate for the effect of vitamin $\mathrm{C}$ on people under heavy acute physical stress is unjustified, he should submit a detailed criticism to the Cochrane Database. Then we will either improve our review according to his suggestions or openly describe our countercomments.

In addition to the two missing vitamin $\mathrm{C}$ and common cold trials with participants under physical exertion $(8,9)$, Nieman ignores other trials that are relevant when considering the effect of antioxidants on physically stressed people. We published a Cochrane review on vitamin $\mathrm{C}$ and pneumonia, and we identified a trial with US Marine recruits in which $2 \mathrm{~g}$ /day vitamin $\mathrm{C}$ supplementation significantly reduced pneumonia incidence: 7 cases in the placebo group vs. 1 case in the vitamin C group $(10,11)$. Heavy physical exertion is characteristic of recruit training, yet crowding together may also contribute to the increased risk of pneumonia: in one survey Navy and Marine recruits were at 30 times higher risk of hospital admission for pneumonia than were nonrecruits (12). Therefore, the findings with the US Marine recruits (11) are relevant to the question of whether antioxidants might reduce the risk of respiratory infections in physically 
stressed people. A systematic review found that several vitamin $\mathrm{C}$ trials with military personnel or participants under comparable conditions (physical stress and/or crowding) reported a statistically significant effect on the incidence or severity of respiratory infections (13).

Furthermore, Nieman does not discuss any vitamin $\mathrm{E}$ trials with clinical respiratory infection outcomes, although a few have been published. We examined the effect of $50 \mathrm{mg} /$ day vitamin $\mathrm{E}$ supplementation on the risk of common cold and pneumonia in physically stressed participants of the Alpha-Tocopherol, Beta-Carotene [ATBC] Study; this included those who had physically demanding jobs and those who engaged in physical exercise as a leisure-time activity. Vitamin $\mathrm{E}$ had no effect on common cold incidence in either group (14), nor did it have any effect on pneumonia incidence in those who had physically demanding jobs (15). However, vitamin $\mathrm{E}$ reduced the incidence of pneumonia in those who exercised during their leisure time by 50\% (15); furthermore, in this group $(\mathrm{N}=9570)$, there was a statistically significant modification of the vitamin $\mathrm{E}$ effect by physical activity on the job $(\mathrm{P}=0.02)(16)$. Vitamin $\mathrm{E}$ reduced pneumonia risk in those who had light or very light jobs by $76 \%$ (95\% CI: $-90 \%$ to $-41 \%)$, whereas vitamin $\mathrm{E}$ did not differ from the placebo in those who had moderate or heavy jobs $(95 \% \mathrm{CI}:-57 \%$ to $+68 \%)(16)$. This modification of the vitamin E effect by the physical activity on job is consistent with the concept that the body adapts to physical stress arising from a regular workload, whereas sporadic heavy exercise can lead to oxidative stress against which vitamin E may protect under some conditions.

Thus, in his review Nieman ignores several antioxidant trials with clinical outcomes and does not describe the quantitative results of the trials he does cite $(5,7)$. He thereby hampers the reader from drawing his or her own conclusions regarding the published findings. Instead, Nieman discusses the effect of antioxidants on laboratory variables such as cytokine levels, even though they are surrogates. However, as well as being of questionable clinical relevance, surrogate outcomes are often misleading $(17,18)$. Surrogate outcome measures, such as laboratory results, should be avoided, for example, in Cochrane reviews (1).

A number of trials indicate that vitamins $\mathrm{C}$ and $\mathrm{E}$ may affect respiratory infections in physically stressed people and further work is justified to examine their roles in more detail. As regards practical conclusions based on current evidence, it would seem reasonable for people who carry out heavy exercise and concurrently suffer from respiratory infections to test whether vitamin $\mathrm{C}$ might be beneficial for them. Such testing of vitamin $\mathrm{C}$ at the individual level seems sensible because it is safe and cheap.

The situation with vitamin E is more complicated. Although the findings of the ATBC Study indicate that vitamin E may affect pneumonia risk in some physically stressed people, pneumonia is a rare infection in the general population; the common cold was not affected by vitamin $\mathrm{E}$. Furthermore, there are findings which indicate that vitamin E supplementation may be harmful for some people. In the ATBC Study, vitamin E increased the risk of tuberculosis by $72 \%$ in participants who had a high dietary intake of vitamin C (19). Therefore it seems rational to patiently wait for further trials that test the effects of vitamin E supplementation on specifically selected groups of people instead of testing it by personal experimentation. 


\section{References}

1 Higgins JPT, Green S, editors. Cochrane Handbook for Systematic Reviews of Interventions 5.0 [updated February 2008]. http://training.cochrane.org/handbook

2 Nieman DC. Immunonutrition support for athletes. Nutr Rev. 2008;66:310-320.

3 Douglas RM, Hemilä H, Chalker EB, Treacy B. Vitamin C for preventing and treating the common cold. Cochrane Database Syst Rev. 2007;(3):CD000980. http://dx.doi.org/10.1002/14651858.CD000980.pub3

4. Peters EM, Goetzsche JM, Grobbelaar B, Noakes TD. Vitamin C supplementation reduces the incidence of postrace symptoms of upper-respiratory-tract infection in ultramarathon runners. Am $\mathbf{J}$ Clin Nutr. 1993;57:170-174. http://www.ajcn.org/cgi/content/abstract/57/2/170

5. Peters EM, Goetzsche JM, Joseph LE, Noakes TD. Vitamin C as effective as combinations of antioxidant nutrients in reducing symptoms of upper respiratory tract infection in ultramarathon runners. South African J Sports Medicine. 1996;11(March):23-27. http://www.mv.helsinki.fi/home/hemila/CC/Peters 1996 ch.pdf

6. Moolla ME. The effect of supplemental anti-oxidants on the incidence and severity of upper respiratory infections in Ultra Marathon runners [MSc thesis]. Cape Town, South Africa: University of Cape Town; 1996. http://www.mv.helsinki.fi/home/hemila/CC/Moolla_1996.pdf

7. Himmelstein SA, Robergs RA, Koehler KM, Lewis SL, Qualls CR. Vitamin C supplementation and upper respiratory tract infections in marathon runners. Journal of Exercise Physiology online. 1998;1(2). http://www.mv.helsinki.fi/home/hemila/CC/Himmelstein_1998.pdf

8. Ritzel G. Critical analysis of the role of vitamin $\mathrm{C}$ in the prevention and treatment of the common cold [in German]. Helv Med Acta. 1961;28:63-68. http://www.mv.helsinki.fi/home/hemila/T3.pdf

9. Sabiston BH, Radomski MW. Health Problems and Vitamin C in Canadian Northern Military Operations. DCIEM Report No. 74-R-1012. Downsview, Ontario, Canada, Defence Research Board, Defence and Civil Institute of Environmental Medicine, 1974. http://www.mv.helsinki.fi/home/hemila/CC/Sabiston_1974_ch.pdf

10 Hemilä H, Louhiala P. Vitamin C for preventing and treating pneumonia. Cochrane Database Syst Rev. 2007;(1):CD005532. http://dx.doi.org/10.1002/14651858.CD005532.pub2

11. Pitt HA, Costrini AM. Vitamin C prophylaxis in marine recruits. JAMA. 1979;241:908-911. http://dx.doi.org/10.1001/jama.1979.03290350028016

12 Pazzaglia G, Pasternack M. Recent trends of pneumonia morbidity in US Naval personnel. Mil Med. 1983;48:647-651. http://www.mv.helsinki.fi/home/hemila/CP/Pazzaglia_1983 ch.pdf

13 Hemilä H. Vitamin C supplementation and respiratory infections: a systematic review. Mil Med. 2004;169:920-925. http://dx.doi.org/10.7205/MILMED.169.11.920

14 Hemilä H, Virtamo J, Albanes D, Kaprio J. Physical activity and the common cold in men administered vitamin E and $\beta$-carotene. Med Sci Sports Exerc. 2003;35:1815-1820. https://doi.org/10.1249/01.MSS.0000093616.60899.92 https://tuhat.helsinki.fi/portal/en/publications/physical-activity-a(127c5369-ca37-4fe9-9c3e-a03310a9926f).html

15 Hemilä H, Kaprio J, Albanes D, Virtamo J. Physical activity and pneumonia in male smokers administered vitamin $\mathrm{E}$ and $\beta$-carotene. Int J Sports Med. 2006;27:336-341. https://doi.org/10.1055/s-2005-865670 https://tuhat.helsinki.fi/portal/en/publications/physical-activity-a(c0188cf0-c221-4d88-b9ff-bbd13d39da0b).html

16 Hemilä H. Do vitamins $\mathrm{C}$ and $\mathrm{E}$ affect respiratory infections? [PhD Thesis]. Helsinki, Finland: University of Helsinki; 2006. pp 56-57, 66-67. http://hdl.handle.net/10138/20335

17 Fleming TR, DeMets DL. Surrogate end points in clinical trials: are we being misled? Ann Intern Med. 1996;125:605-613.

18 Rothwell, P. M. External validity of randomised controlled trials: "To whom do the results of this trial apply?" Lancet. 2005;365:82-93.

19 Hemilä H, Kaprio J. Vitamin E supplementation may transiently increase tuberculosis risk in males who smoke heavily and have high dietary vitamin C intake. Br J Nutr. 2008; in press http://dx.doi.org/10.1017/S0007114508923709 